\title{
La jerarquía militar. Conceptos y terminología
}

\author{
JUAN JOSÉ ÁLVAREZ DÍAZ \\ Teniente Coronel CIET/EA \\ jjaldi@telefonica.net
}

\section{INTRODUCCIÓN}

Si hubiera que buscar un concepto con el que se identifique mejor la estructura militar, este no puede ser otro que el de jerarquía; ya que, además de estar integrado en la propia idea de ejército, es el fundamento de su organización.

Sin embargo, escribir sobre la jerarquía tiene sus dificultades, debido a que se trata de uno de estos conceptos que son consustanciales con la naturaleza humana; un concepto que los hombres de todas las épocas, consciente o inconscientemente, han manejado y que, en algunos ámbitos como el militar ha adquirido mayor complejidad y formas de expresión propias. Estas particularidades han generado un léxico diverso y específico para hablar de la jerarquía militar, en el cual hay palabras que no presentan mayores dificultades de interpretación, pero en el cual, como veremos, también hay algunas con significados muy próximos, que hacen difícil apreciar sus diferencias; y otras que, pese a ser muy utilizadas, tienen acepciones poco conocidas.

Las consideraciones anteriores y la importancia de la jerarquía en el ejército, son las razones que motivan este trabajo, cuyo propósito es hablar del concepto de jerarquía y de los términos de los que nos servimos para expresarla, analizando aquellos que podemos calificar como técnicos de la profesión militar, para desbrozar, en lo posible, la enramada de definiciones y significados que el tiempo y el uso han ido construyendo. Para este análisis, además del criterio personal, se han utilizado, como referencia y guía, las directrices de la Real Academia, plasmadas en el Diccionario de la Lengua Española, las contenidas en los principales diccionarios y glosarios militares y los conceptos doctrinales, reflejados en las Ordenanzas de los ejércitos y en las leyes vigentes.

\section{RAZÓN Y ORIGEN DE LA JERARQUÍA}

Investigaciones sobre el cerebro de los primates, realizadas por los antropólogos Robin Dunbar y Leslie Aiello, han concluido en que el tamaño del grupo social tipo, de una determinada especie, está condicionado por el número de relaciones que un individuo de esa especie puede gestionar adecuadamente. A su vez, este número de relaciones depende, en cierta medida, de las dimensiones del cerebro y, más concretamente, de las del neocortex.

Han observado que monos con cerebro pequeño, como los gibones, forman grupos de cuatro o seis individuos, mientras que otros con cerebro de mayor tamaño, como los chimpancés, lo hacen en grupos de cincuenta o más. Por correlación Dunbar estableció que el grupo social humano (homo sapiens) oscila alrededor de los ciento cuarenta y 
ocho (148) individuos. Este número, conocido como número Dunbar, se corresponde, aproximadamente, con el tamaño máximo de los primitivos grupos de cazadores, de los primitivos asentamientos humanos y, también, con el de la principal unidad táctica, por antonomasia, en los ejércitos, desde la más remota antigüedad: la compañía.

Es importante conocer esta cifra ya que determina, como se ha dicho, el número máximo de relaciones que un individuo puede gestionar; y, si el tamaño del grupo es inferior, podemos afirmar que cada uno de los individuos que lo conforman es capaz de establecer relaciones estables con el resto. Estas relaciones entre los individuos son las que proporcionan cohesión y fuerza al grupo, permitiendo que pueda acometer tareas que para un individuo aislado serían imposibles.

El grupo cohesionado es, en sí mismo, una unidad de fuerza que puede acometer múltiples tareas, pero, para que esa fuerza sea utilizada de manera eficaz, el grupo necesitará que alguien lo dirija. Se aprecia esto claramente en la guerra, donde un grupo de hombres cohesionados solo es considerado una unidad de combate si, entre ellos, hay uno que los lidera en virtud de una autoridad natural o conferida, que lo sitúa por encima de todos y lo convierte en su jefe.

Cuando el tamaño del grupo es superior al número Dunbar, la cohesión del mismo se resiente y el individuo ve a su jefe como alguien lejano y a algunos de sus compañeros como desconocidos. No se percibe, con intensidad suficiente, la autoridad del jefe y sus órdenes no siempre llegan directamente a todos. El mando pierde energía y puede llegar a ser cuestionado; la disciplina se relaja.

En una compañía, por lo general, el soldado se siente vinculado fuertemente a sus compañeros, a los mandos intermedios de la misma y a su capitán; y percibe las órdenes de otros mandos superiores, caso de conocerlas, como simples noticias que podrían llegar a afectarle, pero sin sentirse plenamente concernido hasta que su capitán o alguno de los mandos intermedios, que son los únicos a los que ve como jefes naturales, las transforme en verdaderas órdenes para su unidad.

Los oficiales y suboficiales de una compañía, comenzando por su capitán, deben ser conscientes de la importancia que tiene el conocer a todos sus hombres, establecer con cada uno de ellos una relación personal y que estos, a su vez, la establezcan con el resto de sus compañeros; ya que, como se ha dicho, estas relaciones son el fundamento de la cohesión que debe existir entre los soldados de la unidad y las que determinan su fuerza.

Además de por su propio tamaño, la cohesión de un grupo puede ser afectada por otras circunstancias, especialmente por aquellas que ponen en peligro la vida, como el combate. Cuando esto sucede el individuo tiende a buscar su propia salvación olvidándose del resto; de ahí que en el ejército haya que subdividir las compañías en secciones, pelotones y escuadras poniendo al frente de las mismas a tenientes, sargentos y cabos que refuercen la autoridad del verdadero jefe, el capitán, y mantengan la cohesión de estos pequeños grupos de soldados durante el combate.

Cuando es necesario utilizar más individuos en una batalla, las compañías, sin perder sus características de grupo se aúnan en unidades tipo batallón, estos en brigadas o divisiones y, éstas, en cuerpos de ejército. 
La cohesión del conjunto se mantiene ensamblando los distintos grupos que se forman con los respectivos jefes: uno con los capitanes de las distintas compañías de un batallón; otro con los distintos jefes de batallón de una brigada o división; etc. Y de igual manera que sucede en la compañía, el mando, la subordinación y por ende, la disciplina, se ejercen y mantienen dentro de cada uno de ellos. Así sucede, a nivel de batallón, entre el jefe de batallón y sus capitanes de compañía, a nivel de división o brigada, entre el general y sus jefes de batallón, etc.

Esta estructura de los ejércitos, en la que se aprecia una escala con diferentes niveles de autoridad, tiene como razón de ser garantizar el ejercicio del mando, la disciplina, la subordinación y la transmisión de las órdenes. Y hoy sabemos que esta estructura, como se deduce de las investigaciones de Dunbar y Aiello, está determinada, en última instancia, por la limitación que la naturaleza humana tiene para establecer relaciones y gestionar grupos de individuos.

\section{CONCEPTO DE JERARQUÍA}

Jerarquía es un término de origen griego que el Diccionario de la Lengua Española de la Real Academia Española (en adelante DRAE-2001) define como «gradación de personas, valores o dignidades»; lo que permite hablar de la jerarquía de las personas, de la jerarquía de los valores o de la jerarquía de las dignidades. En la antigua Grecia se utilizaba para referirse al orden o gradación de los seres mitológicos, en función de su autoridad y poder; posteriormente, el cristianismo lo aplicó al orden entre los diversos coros de ángeles y, con el tiempo, el concepto se hizo más general.

En las personas, la jerarquía alude a su gradación, ordenada en niveles sucesivos de autoridad, ascendentes o descendentes, denominados niveles jerárquicos; y de la estructura formada por grupos organizados de individuos, situados en distintos niveles jerárquicos y relacionados entre sí, decimos que es una estructura jerárquica.

Con relación a las personas, es necesario recordar otras tres acepciones de la palabra jerarquía, de las cuales las dos primeras no figuran en el DRAE-2001 pero sí están admitidas en el lenguaje y son de uso habitual. La primera es la que identifica jerarquía con nivel jerárquico y nos permite decir, por ejemplo, que «el Papa es la más alta jerarquía de la Iglesia», o que «Fulano tiene ahora mayor jerarquía que hace un año». La segunda es la que identifica jerarquía con el grupo de personas que ocupa los niveles superiores de una organización jerarquizada y la dirige; y nos permite decir frases como, por ejemplo, la siguiente: «la jerarquía de la Iglesia reconoce que se han cometido errores en el pasado». La tercera es la que identifica jerarquía con jerarca (DRAE2001: s. v.), o persona que tiene elevada categoría en una organización, una empresa, etc.; y que nos permite decir, por ejemplo, que «Fulano es un jerarca, o una jerarquía, de su empresa».

La jerarquía de las personas se caracteriza por constituir un ordenamiento en función de la autoridad y siendo atributos de la autoridad, el Poder, la Responsabilidad, la Consideración y la Precedencia, a cada nivel jerárquico o de autoridad le corresponderá una determinada medida de poder, responsabilidad, consideración y precedencia que 
será superior a la de aquellas personas que estén por debajo en la escala jerárquica e inferior a la de aquellas otras que estén por encima.

Y esta jerarquía de las personas puede decirse que es la combinación de otros dos tipos de jerarquía, claramente diferenciados: jerarquía individual y jerarquía circunstancial.

La jerarquía individual es el ordenamiento que se establece en función de la autoridad que tiene cada persona, por razón de su linaje, por haberle sido conferida o por haberla adquirido por sí misma; la jerarquía circunstancial es el ordenamiento que se establece en función de la autoridad que cada persona adquiere temporalmente, por estar asociada a su puesto de trabajo, cargo, destino, etc.

La jerarquía de las personas está presente en todos los ámbitos de la sociedad pero se estructura de manera distinta. En la mayoría de ellos suele prevalecer la jerarquía circunstancial frente a la individual, como sucede, por ejemplo, en el ámbito de la empresa, donde el nivel de autoridad de una persona en la misma depende, básicamente, del puesto de trabajo que ocupa y, cuando cambia de un puesto a otro, pierde la autoridad y poder que tenía en el antiguo y adquiere la que le confiere el nuevo.

La jerarquía de las personas que prevalece en el ámbito familiar o de las relaciones sociales es la jerarquía de carácter individual; jerarquía que, como se ha dicho, depende, básicamente, del nivel de autoridad que cada persona ha adquirido por sí misma, en virtud de sus propias cualidades, méritos, fama, etc., o que ha heredado y tiene por su linaje y posición social.

En otros ámbitos o, para ser más precisos, instituciones, como son, por ejemplo, la Iglesia o el Ejército, además de la jerarquía de carácter circunstancial, prevalece en ellas una jerarquía individual que es función del nivel de autoridad que la institución confiere a cada uno de sus miembros. Esta jerarquía individual las vertebra estructuralmente y, por ello, estas instituciones reciben el calificativo de jerárquicas o jerarquizadas.

En las instituciones jerárquicas los miembros están encuadrados en escalas de niveles de autoridad o niveles jerárquicos que presentan un orden ascendente. A cada miembro de la institución le es asignado un determinado nivel jerárquico $\mathrm{y}$, con el tiempo, podrá ir ascendiendo por la escala, en función de sus méritos, de su antigüedad, por elección, por selección, etc.

\section{LA JERARQUÍA MILITAR}

Dicen las vigentes Reales Ordenanzas para las Fuerzas Armadas ${ }^{1}$ :

Artículo 9. Jerarquía.

El militar desempeñará sus cometidos con estricto respeto al orden jerárquico militar en la estructura orgánica y operativa de las Fuerzas Armadas, que define la situación relativa entre sus miembros en cuanto concierne a mando, subordinación y responsabilidad. Los que ocupan los diversos niveles de la jerarquía están investidos de autoridad en razón de su cargo, destino o servicio y asumirán plenamente la consiguiente responsabilidad. La autoridad implica el derecho y el deber de tomar decisiones, dar órdenes y hacerlas cum-

\footnotetext{
${ }^{1}$ Real Decreto 96/2009, de 6 de febrero.
} 
plir, fortalecer la moral, motivar a los subordinados, mantener la disciplina y administrar los medios asignados.

Nada mejor que la lectura de este artículo para apreciar la importancia que tienen en la milicia la jerarquía y los conceptos relacionados con la misma. Jerarquía que, como se ha dicho, en las instituciones jerarquizadas como el ejército, tiene dos expresiones diferentes: jerarquía circunstancial y jerarquía individual.

Si analizamos el artículo anterior, podemos deducir que, en el ejército, la jerarquía individual viene dada por «la situación relativa entre sus miembros en cuanto concierne a mando, subordinación y responsabilidad» o, dicho de otra manera por la posición que se ocupa en el escalafón militar. Y para estar investido de autoridad efectiva es necesario, como también apunta la ordenanza, que el militar esté desempeñando un cargo, destino o servicio. Desempeño que le proporciona, además, una jerarquía militar circunstancial que se añade a la individual.

Esta jerarquía individual del militar, podemos clasificarla en jerarquía militar ordinaria y extraordinaria; siendo la jerarquía militar ordinaria, aquella que incluye los niveles jerárquicos habituales que va alcanzando, sucesivamente, a lo largo de su carrera profesional; y jerarquía militar extraordinaria, aquella que incluye niveles jerárquicos que no son habituales en la carrera militar y/o se conceden como premio.

Los conceptos relacionados con las diferentes manifestaciones de la jerarquía militar (ordinaria, extraordinaria y circunstancial), se expresan mediante un léxico que está formado por algunas palabras que podemos considerar como técnicas de la milicia y por otras que son utilizadas, también, en el lenguaje común, pero que tienen acepciones particulares en este ámbito. Veámoslas en la siguiente tabla:

\begin{tabular}{|c|c|c|c|}
\hline \multicolumn{2}{|c|}{ CONCEPTOS DE LA JERARQUÍA MILITAR } & \multirow{2}{*}{$\begin{array}{c}\text { CONCEPTOS ASOCIADOS } \\
\text { A LA JERARQUÍA MILITAR }\end{array}$} \\
\hline ORDINARIA & EXTRAORDINARIA & CIRCUNSTANCIAL & Antigüedad \\
\hline Jerarquía & Título & Cargo & Consideración \\
\hline Grado & Dignidad & Mando & Distinción \\
\hline Categoría & & Servicio & Condición \\
\hline Graduación & & & Asimilación \\
\hline Empleo & & & Situación \\
\hline Clase & & & Retiro \\
\hline Rango & & & \\
\hline
\end{tabular}

En los siguientes apartados iremos analizando, uno a uno, todos estos conceptos.

\section{CONCEPTOS DE LA JERARQUÍA MILITAR ORDINARIA}

\subsection{Grado}

El DRAE-2001 define grado, en la acepción que nos afecta, como

6. m. Cada lugar de la escala en la jerarquía de una institución, especialmente en la militar. 
En el ejército, por consiguiente, grado no es otra cosa que cada una de las jerarquías o niveles de autoridad que son una realidad en el escalafón militar ${ }^{2}$. Así, por ejemplo, son grados militares, general de división, teniente, sargento o cabo mayor; y no son grados militares las jerarquías o niveles de autoridad de carácter circunstancial que están asociados a un mando, cargo o servicio, como por ejemplo: comandante general, oficial de vuelos, o capitán de cuartel, ni tampoco, las jerarquías o niveles de autoridad de carácter extraordinario que están asociados a dignidades militares, como, por ejemplo, la de generalísimo, o a títulos militares, como, por ejemplo, el de almirante de Castilla, porque, aun habiendo sido jerarquías militares, nunca han pertenecido al escalafón.

\subsection{Categoría}

El DRAE-2001 define categoría como

1. f. Cada una de las clases establecidas en una profesión, carrera o actividad.

2. f. Condición social de unas personas respecto de las demás.

Y en la jerarquía militar, categoría es cada una de las clases en las que se agrupan los distintos grados militares.

La vigente Ley 39/2007, de 19 de noviembre, de la carrera militar establece cuatro categorías militares ${ }^{3}$ :

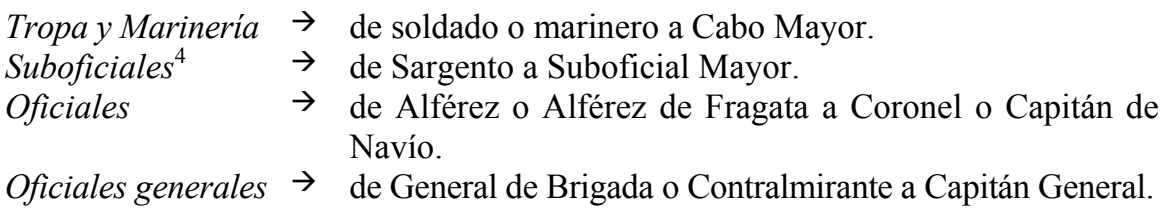

A cada categoría militar corresponde una determinada consideración militar, por lo que podemos decir que la categoría militar es un indicativo del estatus profesional del militar y de su condición social. Y así se dice, por ejemplo, que fulano tiene una elevada categoría militar, para significar la importancia de su estatus profesional y condición social.

Y aunque la categoría militar expresa jerarquía, no es, propiamente, un indicativo del nivel jerárquico por lo que, en el ejército al menos, no debiera confundirse con el grado o el empleo militar; error, que suele darse muy frecuentemente. Por ejemplo, no

\footnotetext{
${ }^{2}$ El concepto de grado militar existe en España desde el siglo XVIII.

${ }^{3}$ Hasta 1989, existió una categoría intermedia entre la de Oficiales y la de Oficiales generales, denominada de Jefes en todos los ejércitos, que estaba constituida por los empleos de comandante, teniente coronel y coronel y, en la Armada, por los de capitán de corbeta, capitán de fragata y capitán de navío. La Ley 17/1989 cambió el nombre de esta categoría por el de Oficiales superiores y creo una categoría intermedia entre la de Suboficiales y la de Oficiales, denominada de Suboficiales superiores, que estaba constituida por los empleos de subteniente y suboficial mayor. Estas dos categorías desaparecieron con la Ley 17/1999.

${ }^{4}$ La categoría de Suboficiales se creó por Ley de 4 de diciembre de 1931, cuyo art. 2, dice: «Se crea el Cuerpo de Suboficiales del Ejército, que serán, auxiliares del mando y constituirán categoría intermedia entre el Cuerpo de Oficiales y las clases de tropa».
} 
es correcto decir que un militar tiene categoría de teniente coronel; lo correcto es decir que ese militar tiene categoría de oficial y empleo o grado de teniente coronel. ${ }^{5}$

\subsection{Graduación}

El DRAE-2001 define graduación, en la acepción que nos afecta, como:

3. f. Mil. Categoría de un militar en su carrera.

Esta definición no es muy afortunada, pues lleva a confundir fácilmente graduación con categoría militar (Tropa y Marinería, Suboficiales, Oficiales y Oficiales generales), cuando, en este caso, la palabra 'categoría' no alude a la categoría militar sino, simplemente, al nivel jerárquico.

Creemos que es más preciso definir graduación como «el grado militar que representa la divisa».

Definición que, además, nos permite entender con facilidad porque graduación y grado se utilizan, habitualmente, como palabras sinónimas. Por ejemplo: «Fulano tiene grado de brigada $\gg \rightarrow\langle$ Fulano tiene graduación de brigada».

La graduación militar, representada en las divisas del uniforme, es, al igual que sucede con la categoría militar, un indicativo del estatus profesional del militar y de su condición social; siendo, graduación y categoría, desde este punto de vista y solo desde éste, palabras sinónimas. Y así se dice, por ejemplo: «Fulano tiene una elevada graduación militar»o «Fulano tiene una elevada categoría militar», para significar la importancia de su estatus profesional y condición social.

Así pues, y resumiendo, decimos que graduación es un término polisémico que se puede utilizar, según los casos, como indicativo del nivel jerárquico o como indicativo del estatus profesional y condición social del militar.

\subsection{Empleo}

El DRAE-2001 define empleo, en la acepción que nos afecta, como:

3. m. Mil. Jerarquía o categoría personal.

De nuevo nos encontramos con una definición de la Academia demasiado escueta y poco precisa, que hace necesario un estudio que nos aporte más información.

Curiosamente, aun siendo éste uno de los términos más utilizados en la milicia, la mayoría de los diccionarios militares parecen obviarlo y cuando lo contemplan, simplemente lo hacen equivalente a grado, sin mayor explicación ${ }^{6}$. Sin embargo, el análisis de los textos militares en los que figura, especialmente los de carácter normativo o legislativo, nos demuestra que, empleo no es considerado en el lenguaje militar como sinónimo de grado, aunque en el lenguaje general se utilicen ambos términos como si

${ }^{5}$ Este error lo vemos, incluso, en disposiciones oficiales, como en el Decreto Ley de 16 de junio de 1931, que en sus artículos $2^{\circ}$ y $3^{\circ}$, denomina como categoría los empleos de teniente general y general de división: «Art. $2^{\circ}$. Queda suprimida la categoría de teniente general. / Art. $3^{\circ}$ La categoría más elevada en el Estado Mayor General será la de general de división».

${ }^{6}$ El General Almirante (1989 [1873]: s. v. empleado, empleo) señala textualmente: «Para evitar repeticiones, consúltese los art. Efectivo, Ejercicio, Grado, Reformado, Reemplazo, Propietario, Vivo». 
lo fueran. Y así, en virtud de las diferencias que se aprecian en su utilización, podemos definir empleo militar como «el grado militar que tiene asociados sueldo y competencias sancionadoras».

Actualmente, todos los grados militares (sargento, general de brigada, teniente, etc.) son, también, empleos militares, dado que todos ellos tienen asociados sueldo y competencias sancionadoras ${ }^{7}$. Sin embargo, esto no fue siempre así, como veremos en el apartado dedicado al dualismo.

La diferencia entre grado y empleo es fácilmente apreciable en las disposiciones sobre grado eventual y empleo eventual que figuran en las últimas leyes de la profesión militar, como la derogada Ley 17/1999 de Régimen del Personal Militar Profesional, que contemplaba la concesión de simples grados militares, con carácter eventual:

Artículo 14. Grados militares.

1. Cuando por necesidades del servicio se designe a un militar para ocupar un puesto en organizaciones internacionales que corresponda al empleo superior al suyo, el Ministro de Defensa, a propuesta del Jefe del Estado Mayor de la Defensa, le podrá conceder, con carácter eventual, el grado militar correspondiente a ese empleo superior, en el que tendrá las atribuciones y usará las divisas del mismo, excepción hecha de las competencias sancionadoras y de las retribuciones, que serán las correspondientes a su empleo efectivo. Dicho grado lo conservará hasta ascender al citado empleo superior o hasta el momento de su cese en el mencionado puesto.

La entrada de España en organismos internacionales como la OTAN, supuso que los militares españoles empezasen a ocupar cargos de responsabilidad en estos organismos, como la presidencia de agencias o comisiones en las que los representantes militares de los diferentes países podían tener igual o mayor empleo. En ocasiones, la persona que el ministerio consideraba idónea para ocupar uno de estos cargos carecía de jerarquía suficiente y era necesario concederle un grado eventual superior a su empleo, tal y como se estableció en el artículo que acabamos de ver. Sin embargo, el hecho de no otorgar a estos militares el sueldo y las atribuciones sancionadoras correspondientes a la alta responsabilidad que se les encomendaba, fue, con el tiempo, considerado como un error que habría de corregir la vigente Ley 39/2007, de 19 de noviembre, de la carrera militar.

Esta ley, en lugar de grados contempla la concesión de empleos con carácter eventual, con todas sus atribuciones y prerrogativas, para las mismas circunstancias que consideraba la ley anterior:

Artículo 22. Empleos con carácter eventual

1. Cuando por necesidades del servicio se designe a un militar para ocupar un puesto en organizaciones internacionales $u$ otros organismos en el extranjero que corresponda al empleo superior al suyo, el Ministro de Defensa, a propuesta del Jefe de Estado Mayor de la Defensa, podrá conceder con carácter eventual dicho empleo con sus atribuciones, retribuciones y divisas.

\footnotetext{
${ }^{7}$ Esta competencia está regulada por el Régimen Disciplinario de las Fuerzas Armadas.
} 
Conservará el empleo eventual hasta ascender a ese empleo o hasta el momento de su cese en el mencionado puesto.

\subsubsection{El dualismo}

Dualismo es un término con el que se designó la coexistencia de empleo y grado militar en un mismo individuo; aunque su origen se remonta al siglo XVIII la generalización del dualismo llegó en el siglo XIX, como consecuencia de constituirse en escalas cerradas, las de los oficiales de los cuerpos de Estado Mayor, Artillería e Ingenieros, y no aceptar sus componentes ningún ascenso que no fuera por rigurosa antigüedad, a diferencia de lo que sucedía en las escalas de oficiales de las armas generales, Infantería y Caballería, donde los ascensos eran por elección y como premio, supuestamente, a las cualidades y los méritos de guerra o de otra clase.

Pero para no dejar sin reconocimiento a aquellos oficiales de los mencionados cuerpos que destacaban por su heroísmo o por otros méritos, se inventó el concederles grados superiores a su empleo, que no tenían efectos económicos pero que les proporcionaban mayor jerarquía y, consecuentemente, mayor poder, responsabilidad, consideración y prelación. Pronto esto se extendió al resto de armas, cuerpos o institutos, incluida la Guardia Civil.

Inicialmente los grados podían ser de Infantería o Caballería, a elección del agraciado, pero los oficiales de estas armas protestaron y el gobierno dictaminó que los grados serían, simplemente, «de Ejército». Y así, había, por ejemplo, sargentos de infantería graduados de alférez de ejército, capitanes de artillería graduados de teniente coronel de ejército, etc. Con el tiempo, los grados solían hacerse efectivos, esto es, convertirse en empleos.

Sobre el uniforme se llevaban las divisas del empleo y del grado y, cuando concurrían en un mismo lugar fuerzas del mismo cuerpo o arma, el mando de las mismas correspondía al oficial de mayor graduación y si había dos o más oficiales de igual graduación, correspondía al de mayor antigüedad en el disfrute del grado porque, como dice una expresión de aquellos años que todavía se sigue utilizando, «la antigüedad es un grado».

Los oficiales de las armas (Infantería y Caballería) podían tener empleo y grado o solo empleo; sin embargo, todos los oficiales de los cuerpos de Casa Real (Guardias de Corps, Carabineros Reales y Guardias de Infantería), del Cuerpo de Artillería, del Cuerpo de Ingenieros y de la Real Armada tenían, por defecto, un grado «de ejército» asociado a su empleo. Así, por ejemplo, un teniente de carabineros tenía grado de capitán de ejército; un capitán de fragata tenía grado de teniente coronel de ejército, etc. En el caso de la Armada estas equivalencias todavía persisten.

La concesión de grados militares que, desde sus inicios, fue causa de malestar entre los oficiales por los agravios que ocasionaba, quedó suprimida definitivamente en 1889 por la Ley Adicional a la Constitutiva del Ejército de 19 de julio ${ }^{8}$, y, desde entonces, la

${ }^{8}$ Ya en 1811, las Cortes de Cádiz, por Orden de 27 de agosto de 1811, determinaron «prohibir absolutamente por punto general la concesión de grados militares»; sin embargo, la concesión de grados continuó, fracasando todos los intentos realizados para suprimirlos en años posteriores, incluso el que hizo 
diferencia entre grado y empleo militar dejó de percibirse con claridad, por lo que, a menudo, se utilizan como sinónimos sin serlo, verdaderamente.

Los conceptos de grado y empleo militar son muy importantes en el ejército y es necesario conocer su verdadero significado, pues, aunque suelen utilizarse habitualmente como si fueran sinónimos, en puridad no lo son.

\subsection{Clase}

La palabra clase, muy enraizada en las antiguas ordenanzas del ejército, se ha utilizado, desde el Renacimiento, para referirse a cualquier conjunto de militares, susceptible de ser clasificado por alguna característica. Y así, clase, según conviniera, lo mismo podía equivaler a empleo o grado, a categoría o a situación.

Se decía en el siglo XIX, por ejemplo, que el Tambor Mayor era «de la clase de Sargentos» (empleo o grado); que los Comandantes de Presidio eran «de la clase de Jefes» (categoría ${ }^{9}$ ); y se hablaba, también, «de la clase de Retirados» $\left(\right.$ situación $^{10}$ ). Sin embargo, tradicionalmente, el término clase se ha utilizado, preferentemente, para referirse a la tropa en sustitución de los términos categoría, empleo o grado. Y así, mientras que, con relación a los oficiales o suboficiales, se hablaba siempre de categoría de oficiales o de suboficiales, con relación a la tropa, siempre se decía la clase de tropa; y cuando lo que se quería era aludir a los empleos o grados de la misma (soldado de $1^{\text {a }}$, cabo o cabo primero ${ }^{11}$ ) se hablaba de las clases de tropa.

Clase, al igual que sucede con categoría, es, en la mayoría de los casos, un término indicativo de jerarquía militar. Y, aunque desapareció oficialmente del lenguaje militar en 1978, con la promulgación de las Reales Ordenanzas de SM el Rey Juan Carlos I, y tampoco figura ya en ordenanzas, reglamentos u escritos oficiales, el gran arraigo que tiene en el ejército ha hecho que todavía hoy se siga utilizando.

\subsection{Rango}

Rango es una antigua palabra ${ }^{12}$, cuya definición en el DRAE-2001, en la acepción que nos afecta, es muy similar a la de 'graduación':

1. m. Categoría de una persona con respecto a su situación profesional o social.

Narváez en 1866 por Real Decreto de 30 de julio, cuyo art. 3 decía, taxativamente, «Queda abolida para en adelante la concesión de grados superiores á los empleos efectivos». Pero, tras la revolución de 1868 el dualismo fue restablecido de nuevo.

${ }^{9}$ La categoría de Jefes, que englobaba los empleos de comandante, teniente coronel y coronel, y sus equivalentes en la Armada de capitán de corbeta, capitán de fragata y capitán de navío, estuvo vigente hasta 1989 (Ley 17/1989), en que cambió su denominación por la de Oficiales Superiores. Desapareció en 1999 (Ley 17/1999), incorporándose sus empleos a la categoría de Oficiales.

10 Retirado es, actualmente, una situación administrativa y no una situación militar, dado que el personal retirado ya no tiene la condición militar. Véase infra el apartado dedicado al Retiro.

11 Hasta 1934 (Ley de 4 de julio), en que fue incorporado a la nueva clase de Suboficiales, el empleo de sargento también estaba incluido entre las clases de tropa.

${ }^{12}$ La primera referencia de rango que figura en el Corpus Diacrónico del Español (en adelante CORDE) está en un documento del siglo XII, y la primera referencia que figura en este mismo corpus en la que, claramente, alude al estatus, se encuentra en un documento de finales del siglo XV. 
Etimológicamente, la palabra rango tiene el mismo origen que rancho, ya que ambas proceden del francés y tienen como raíz común hring, palabra perteneciente al idioma de los francos que significa círculo o corro de gente. Era costumbre entre los francos el formar grupos de familiares y amigos que trabajaban y cazaban juntos y se ayudaban mutuamente. Estos grupos se juntaban para comer formando un círculo alrededor de las viandas o de la caldera en la que se habían cocinado. A una persona se la identificaba con el círculo al que pertenecía. Las diferencias de poder e influencia social que había entre unos y otros círculos es lo que proporcionó a hring y, por ende, a rango el sentido de estatus.

$\mathrm{Y}$, al igual que 'graduación', 'rango' lo mismo puede aludir al nivel jerárquico que al estatus profesional, por lo que, en el ejército, son palabras sinónimas. Y lo mismo podemos decir: «Fulano tiene mayor rango militar que Mengano», que «Fulano tiene mayor graduación militar que Mengano»; o «Zutano es oficial de alto rango», que «Zutano es oficial de alta graduación», etc.

Sin embargo, mientras que graduación, en las acepciones que estamos considerando, es un término propio del ejército, la palabra rango se utiliza en otros ámbitos, por lo que es necesario, en ocasiones, añadirle un calificativo, tal que militar, eclesiástico, judicial, etc., para que quede claro aquel en el que la estamos utilizando. Por ejemplo, si en el primero de los ejemplos anteriores suprimimos el calificativo militar y decimos, simplemente, «Fulano tiene mayor rango que Mengano», no quedaría claro en que ámbito sucede esto; sin embargo, si decimos que «Fulano tiene mayor graduación que Mengano», todo el mundo presupone que se está hablando de dos militares. Y otra diferencia entre graduación y rango es que esta última, además de a personas, también se aplica a cosas; por ejemplo: «Esta ley es de rango constitucional».

Se presupone que la palabra rango existe en español desde el siglo XI, aunque las referencias escritas más antiguas son del siglo $\mathrm{XII}^{13}$. Hasta épocas recientes el uso habitual de rango era para indicar estatus, importancia, dignidad, primacía, valor, etc., pero no para indicar nivel jerárquico militar o grado.

Un refrán militar español dice «Cuanto mayor es el grado, mayor es el rango», para significar que, a mayor grado militar, mayor categoría y consideración social; poniendo, con ello, de manifiesto que 'grado' y 'rango' no son lo mismo. Sin embargo, hoy en día esto ya no es así y la palabra rango (militar) se considera, también, sinónima de la palabra grado (militar).

La razón por la cual se produjo esta sinonimia tiene que ver con la palabra inglesa rank, que en este idioma se utiliza para referirse al grado militar. La mayoría de los traductores de libros o documentos de temática militar, la han trasladado al español como rango, en vez de como grado y el tiempo ha hecho el resto. Y así, hoy se dice, por ejemplo: «Fulano tiene rango de capitán», «Mengano ha ascendido al rango de cabo», etc. 
4.7. Uso de jerarquía, categoría, grado, graduación, rango y empleo

Las palabras jerarquía, grado, graduación, rango y empleo tienen, como se ha podido apreciar, una gran proximidad semántica por lo que, frecuentemente, son utilizadas como sinónimas; sin embargo, las diferencias que existen entre ellas hacen que sea aconsejable, según los casos, utilizar unas y no otras.

Utilicemos, preferentemente,

- Jerarquía, en frases en las que se quieran subrayar conceptos como la autoridad o el poder. Por ejemplo: «El General N fue tratado con los honores correspondientes a su elevada jerarquía militar».

- Empleo, graduación, grado o rango, cuando se aluda al nivel jerárquico. Por ejemplo: «Debido a su valor y excelente comportamiento en campaña, N alcanzó el empleo/grado/graduación/rango de capitán».

- Categoría, graduación o rango en frases en las que se aluda al estatus profesional $\mathrm{y} / \mathrm{o}$ social. Por ejemplo: «N tiene mayor categoría/graduación/rango militar que $\mathrm{M} » ;$ «N es un oficial de elevado rango/graduación/categoría militar».

\section{CONCEPTOS DE LA JERARQUÍA MILITAR EXTRAORDINARIA}

\subsection{Título}

La palabra título es definida por el DRAE-2001, en la acepción que nos afecta, como

5. $m$. Dignidad nobiliaria, otorgada por el rey, normalmente transmisible, como la de conde, marqués, duque.

La guerra y las armas están en el origen de los primeros títulos nobiliarios: marqués, conde, señor, etc., ya que, especialmente en la Edad Media, los monarcas los concedían a algunos de sus vasallos como premio a su esfuerzo en la guerra o a su apoyo y contribución para lograr la victoria.

La mayoría de los títulos medievales conllevaban aparejado el dominio sobre tierras y poblaciones, de cuyas rentas se beneficiaba el noble, y, también, la obligación de defenderlas.

Sin embargo, cuando se habla de títulos de nobleza militares no se alude a estos títulos, sino a aquellos otros que concedía el monarca a quienes merecían su confianza para dirigir los ejércitos. Fueron estos, los de Condestable ${ }^{14}$ y Almirante ${ }^{15}$ y los hubo en casi todos los reinos cristianos peninsulares: Condestable de Castilla, Condestable de Navarra, Condestable de Aragón, Almirante de Aragón, Almirante de Castilla, Almirante de las Indias o de la Mar Océana ${ }^{16}$, Gran Almirante de España ${ }^{17}$, etc.

${ }^{14}$ El Título militar de Condestable de Castilla, de influencia francesa, fue creado por el rey Juan I en 1382, en sustitución del cargo de Alférez Mayor del Reino.

${ }^{15}$ El título militar de Almirante de Castilla fue creado por el rey Fernando III en 1247.

${ }^{16}$ Título militar que los Reyes Católicos concedieron a Cristóbal Colón.

${ }^{17}$ El Título de Gran Almirante de España es una singularidad, ya que se trata de un título militar de nobleza a la antigua usanza, con tratamiento de Alteza Serenísima, que le fue concedido a Manuel Godoy por el Rey Carlos IV en 1807, época en la que ya no era costumbre hacerlo, por ser más acorde con 
Los títulos militares fueron jerarquías militares de naturaleza nobiliaria que tenían todas las prerrogativas de la nobleza, entre ellas el derecho a uso de escudo de armas y mote. Muchos de ellos fueron concedidos, inicialmente, con carácter vitalicio, transformándose en hereditarios posteriormente ${ }^{18}$.

\subsection{Dignidad}

La palabra dignidad, del latín DIGNITAS y muy antigua en castellano ${ }^{19}$, es definida por el DRAE-2001, en la acepción que nos afecta, como

4. $f$. Cargo o empleo honorífico y de autoridad.

Como se puede apreciar es una definición escueta, pero en la que hay dos sustantivos y dos calificativos que encierran mucho significado: las palabras cargo y empleo expresan jerarquía; y las palabras honorífica y autoridad apuntan a que es elevada, dotada de gran consideración y efectiva o con verdadero poder ${ }^{20}$.

$\mathrm{Y}$ aunque en el ejército, esta definición puede decirse que es de aplicación a todos los empleos de la categoría de Generales y Almirantes, lo habitual en España, desde el siglo XVIII, ha sido reservar la expresión dignidad militar, únicamente, para el máximo empleo de la jerarquía militar que, tradicionalmente, ha sido el de Capitán General. Veamos, por qué.

Antes del siglo XVIII, solían calificarse como dignidad los títulos de nobleza y cualquier cargo o empleo del estado, del Ejército, de la Iglesia o de otra institución relevante, que llevase aparejado algún tipo de reconocimiento social. Como dignidades militares eran reconocidas en la Edad Media, los títulos de nobleza militares y las jerarquías de las órdenes militares (Gran Maestre, Prior, Caballero, etc.) y en el Renacimiento, con la aparición de los ejércitos permanentes, era calificado como dignidad militar cualquier cargo o empleo militar cuyo nivel jerárquico fuera igual o superior a capitán ${ }^{21}$.

Sin embargo, en 1715 el rey Felipe V creó los empleos militares de Capitán General de los Reales Ejércitos y Capitán General de la Real Armada ${ }^{22}$ para, a imitación de los

los tiempos la concesión de la dignidad de Capitán General, de la que también disfrutaba Godoy desde 1793, o la de Generalísimo que le había sido otorgada en 1801.

${ }^{18}$ El título de Condestable de Castilla se hizo hereditario a partir de 1473, año en el que Enrique IV se lo concedió a Pedro Fernández de Velasco y se mantuvo en la misma familia hasta el siglo XVIII, siendo José Fernández de Velasco Tovar (1696-1713) el último que lo ostentó.

El título de Almirante de Castilla se hizo hereditario a partir de 1405, año en el que Enrique III se lo concedió a Alfonso Enríquez y se mantuvo en la misma familia, hasta el año 1705, siendo Juan Tomás Enríquez de Cabrera el último que lo ostentó.

El título de Almirante de la Mar Océana, concedido a Cristóbal Colón, era hereditario y sigue vigente a efectos, únicamente, honoríficos; lo ostenta en la actualidad Cristóbal Colón de Carvajal y Gorosábel.

${ }^{19} c$ 1230. Primera referencia en CORDE.

${ }^{20}$ Se exceptúan de esto último las dignidades concedidas, únicamente, a título honorífico, que carecen de autoridad efectiva.

${ }^{21}$ En pleno Siglo de Oro el lexicógrafo Sebastián de Covarrubias en su Suplemento al Tesoro de la lengua española castellana (c 1611), refiriéndose al coronel, señala que «es dignidad militar».

${ }^{22} \mathrm{Al}$ margen de que, a partir del siglo XVIII se concediera como empleo y dignidad militar, la jerarquía de Capitán General ha existido en los ejércitos españoles, como cargo, desde el siglo XIII (primeras referencias) hasta finales del siglo XX en que desaparecen las Capitanías Generales de Región Militar. Y por esta razón, es necesario no confundir a aquellos que alcanzaron la dignidad de Capitán General con 
mariscales de Francia, ser otorgados, con carácter vitalicio, a quien conviniera a S. M. y a generales o almirantes que hubieran prestado servicios extraordinarios a la nación. Estos empleos, que representan el nivel más elevado de la jerarquía militar, fueron referidos desde su origen como dignidades militares, y también en cuantas disposiciones posteriores se los mencionaba, por lo que, con el tiempo, el uso de esta denominación fue quedando restringida a los mismos. Véase, a modo de ejemplo, el Decreto Ley de 16 de junio de 1931, por el que se suprimen:

Artículo $1^{\circ}$. Queda suprimida en el Estado Mayor General la dignidad de Capitán General del Ejército.

Posteriormente, por disposición de 18 de julio de 1938, el gobierno de la República las restableció:

Artículo $1^{\circ}$. Se restablece la dignidad de Capitán General en el Ejército y en la Armada, con todos los honores, privilegios y prerrogativas de que gozaban [los Capitanes Generales] antes de ser suprimida.

Mientras estuvieron vigentes, la dignidad de Capitán General tuvo asociadas todas las prerrogativas de la nobleza, salvo la de ser transmisible.

Se ha llamado a los Capitanes Generales, príncipes de la milicia, porque a efectos protocolarios y de consideración social, su dignidad se consideraba equivalente a la de un príncipe.

Desde 1989, el nivel jerárquico de capitán general corresponde en exclusiva al rey $^{23}$, como así, lo determinó la Ley 17/1989 reguladora del régimen del personal militar profesional, en su Artículo $2^{\circ}$ («Mando supremo de las fuerzas armadas»):

El mando supremo de las Fuerzas Armadas corresponde a Su Majestad el Rey, quien tiene el empleo de Capitán General del Ejército de Tierra, de la Armada y del Ejército del Aire.

Además de la dignidad de Capitán General, también debemos considerar como dignidad militar, o más bien político-militar, la de Generalísimo ${ }^{24}$, o general de generales de todos los ejércitos, armas y cuerpos, que les fue concedida oficialmente a Manuel Godoy en 1801, a Arturo de Wellesley (Duque de Wellington) en 1812, al Infante don Carlos María Isidro en 1814, a Rafael Maroto, a Baldomero Espartero en 1838, a José Miaja en 1939 y al anterior Jefe del Estado, Francisco Franco en $1936^{25}$. Salvo en el

quienes, simplemente, ejercieron un cargo con igual denominación, como sucedía, por ejemplo, con los que mandaban una demarcación militar denominada Capitanía General, que, siendo Tenientes Generales de empleo, eran referenciados, en virtud de su cargo, como capitanes generales; y así se decía, por ejemplo: «el Capitán General de Cataluña presidió el acto de...».

${ }^{23}$ La última persona que recibió la dignidad de Capitán General (honorifico), antes de ese año, fue el Excmo. Sr. Manuel Gutiérrez Mellado.

${ }^{24}$ Generalísimo, en tanto que simple denominación, ha sido habitual desde el Renacimiento para referirse al cargo de jefe supremo de un ejército o conjunto de ejércitos en el que había varios generales. Se denominó así a Don Juan de Austria, cuando comandó la escuadra aliada en Lepanto, y lo utiliza, también, el Maestre de Campo Sancho de Londoño en sus famosas ordenanzas de 1568.

${ }^{25}$ Francisco Franco fue nombrado Generalísimo de los ejércitos de Tierra, Mar y Aire por acuerdo de la Junta de Defensa Nacional, el 27 de septiembre de 1936. Entonces era General de División. Posteriormente, en 1938, se autoconcedió la dignidad de Capitán General. 
caso del Infante, el nombramiento se produce como consecuencia de una guerra que, o bien ha finalizado, caso de Godoy ${ }^{26}$, o está en su apogeo, casos de Wellington, Espartero, Maroto, Miaja y Franco. Y con el objetivo de dotar a los ejércitos de un mando supremo único.

Una característica de las dignidades militares es que, aun teniendo los atributos de empleo militar, nunca formaron parte del escalafón, por lo que podríamos definir dignidad militar como

Empleo honorífico y de autoridad en el ejército, que sobrepasa al más elevado de la carrera militar.

\section{CONCEPTOS DE LA JERARQUÍA MILITAR CIRCUNSTANCIAL}

Podemos definir la jerarquía circunstancial, en el ejército, como aquella que incluye los niveles jerárquicos asociados al puesto de trabajo de los militares; siendo éste el que desempeñen por razón de su cargo, destino o servicio ${ }^{27}$.

\subsection{Cargo}

El término cargo es descrito en el DRAE-2001 como

1. $m$. Dignidad, empleo, oficio.

Y desde el punto de vista de la jerarquía, podemos decir que el nivel jerárquico y atribuciones del que ejerce un cargo son las asociadas a la correspondiente dignidad, empleo u oficio.

En el ejército, los cargos militares se corresponden con determinados puestos de trabajo, comisiones o destinos y todo militar que ejerce un cargo tiene la jerarquía y atribuciones asociadas al mismo, además de la jerarquía que tiene por su propio empleo o grado militar.

Los cargos militares, en muchos casos, tienen una denominación parecida a la de determinados empleos o grados, lo que ha llevado a personas no familiarizadas con el ámbito militar, a confundirlos

Así, por ejemplo, son o han sido cargos militares:

- Capitán General de Capitanía o Región Militar. Cargo que era desempeñado por un Teniente General de empleo.

- Comandante General de plaza o archipiélago, como el Comandante General de Baleares o el Comandante General de Melilla. Cargo que es desempeñado por un General de División.

- Comandante de Puesto. Cargo de la Guardia Civil que es desempeñado por un Teniente, Sargento o, incluso, Cabo.

${ }^{26}$ En 1801 con motivo de la breve guerra con Portugal, conocida como la Guerra de las Naranjas, el rey Carlos IV nombra Generalísimo a Godoy, dignidad que le es confirmada a perpetuidad en octubre del mismo año. Esta dignidad se añade a la de Capitán General que disfrutaba desde 1793.

${ }^{27}$ Art. 9 del Real Decreto 96/2009 por el que se aprueban las Reales Ordenanzas para las Fuerzas Armadas: «[...] Los que ocupan los diversos niveles de la jerarquía están investidos de autoridad en razón de su cargo, destino o servicio y asumirán plenamente la consiguiente responsabilidad.[...]». 
- Comandante de buque. Cargo desempeñado por oficiales del Cuerpo General de la Armada.

- Gobernador Militar de provincia. Cargo que era desempeñado por un oficial general.

- Delegado de Defensa. Cargo desempeñado por un coronel o capitán de navío.

- Jefe de Agrupación de Base Aérea, Aeródromo Militar o Acuartelamiento Aéreo. Cargo desempeñado por un oficial general o coronel.

- Jefe de Ala. Cargo desempeñado por un coronel

- $\quad$ Etc.

\subsection{Mando}

Mando es un término que en el ejército tiene varias acepciones. Veamos, como lo define el Glosario de términos militares publicado por el Mando de Adiestramiento y Doctrina del Ejército de Tierra:

\section{MANDO}

1. Significados principales y sus notas características más importantes:

- Poder o autoridad: Autoridad y poder que tiene el superior para dictar órdenes, y hacerse obedecer de sus subordinados.

- Persona: La que ejerce dicho poder o autoridad.

- Estructura o jurisdicción: Se refiere tanto a cada una de las diversas estructuras o jurisdicciones en las que está encuadrada buena parte de nuestro Ejército como a la Autoridad Superior de cada una de ellas (MAPER, MADOC., MALE,...) (DO2-203).

Conforme a la primera de estas definiciones, decimos que alguien tiene mando cuando tiene la autoridad para dictar órdenes y hacerse obedecer de sus subordinados. $\mathrm{Y}$, conforme a la segunda, diremos de esta persona que es un mando militar, lo que significa que tiene graduación superior a la de simple soldado.

Desde el punto de vista orgánico reciben el nombre de mandos, como dice la tercera definición, aquellas estructuras o jurisdicciones en las que se encuadra buena parte del ejército. Estas estructuras o jurisdicciones se caracterizan por su gran tamaño, ya que engloban a decenas de unidades militares y a miles de individuos, y su denominación comienza, precisamente, por esa palabra: Mando de Personal, Mando de Canarias, Mando de Apoyo Logístico, Mando de Artillería Antiaérea, etc.

Pero además de estos grandes mandos, coloquialmente, también recibe la denominación de 'mando'

cualquier cargo militar que se corresponde con determinados destinos, denominados destinos de mando, que tienen asociada la jefatura de una unidad en la que se ejerce mando.

Los destinos de mando son designados por los Jefes de Estado Mayor de los ejércitos y la Armada y su permanencia en ellos durante un determinado tiempo es un requi- 
sito para el ascenso que deben cumplir los oficiales de los cuerpos generales. Son, por ejemplo, destinos de mando, las jefaturas de compañía, batallón, buque de guerra, escuadrilla, ala, división, etc.

Saber mandar es una de las principales aptitudes que deben tener todos los militares, especialmente los oficiales de los cuerpos generales, y, para adquirirla es necesario ejercer el mando, siendo esta la razón por la cual se les exige el paso, durante un tiempo al menos, por esta clase de destinos. Y de aquel oficial que es destinado a uno de ellos se dice, coloquialmente, que «se le ha concedido un mando».

Por lo general los destinos que pertenecen a la estructura civil del Ministerio de Defensa o son ajenos a la estructura militar directamente vinculada a la fuerza como, por ejemplo, la jefatura del Instituto de Historia y Cultura Militar o la dirección del Hospital Central de la Defensa, no reciben la denominación de mandos, aunque tengan, como sucede con algunos, la condición de destinos de mando y se puedan cumplir en ellos los requisitos de mando exigibles para el ascenso.

Del mando, se puede decir que es un cargo genuinamente militar, y el oficial al que se le concede uno, como por ejemplo el mando de un buque de guerra, de un batallón o de una escuadrilla tiene, desde el punto de vista jerárquico, todas las atribuciones que reglamentariamente le están asociadas.

\subsection{Servicio}

Para la definición de servicio, en su acepción militar, podemos servirnos, por ejemplo, del Artículo 184 de las Reales Ordenanzas del Ejército del Aire, ya que la misma es perfectamente válida para el resto de las fuerzas armadas:

A efectos de régimen interior, se denominan servicios las prestaciones personales de duración limitada, conducentes a garantizar la seguridad, la continuidad de la acción del mando y el normal desarrollo de la actividad de las unidades.

El nombramiento para la realización de un servicio confiere, al designado, la autoridad asociada a su desempeño y, por consiguiente, jerarquía. Desde este punto de vista podemos decir que, en el ejército,

'servicio' representa un nivel jerárquico asociado a una prestación personal de duración limitada.

Al igual que sucede con los cargos, hay servicios en el ejército que tienen denominaciones parecidas a las de determinados empleos o grados.

Así, por ejemplo, en el Ejército del Aire son servicios militares:

- Capitán de Día. Servicio desempeñado por capitán, y, en caso necesario, por un Teniente.

- Comandante de la Guardia de Seguridad. Servicio que es desempeñado por un oficial o suboficial.

- Oficial de Vuelo. Servicio que es desempeñado por un oficial (teniente o alférez piloto) y, en su defecto, por un suboficial o un capitán. 
- Oficial de Servicio Interior. Servicio desempeñado por los tenientes y alféreces de la escuadrilla y, en caso necesario, también por subtenientes y brigadas.

- $\quad$ Sargento de Servicio Interior. Servicio desempeñado por los sargentos de la escuadrilla y, en caso necesario, por los cabos primeros.

- Etc.

\section{CONCEPTOS ASOCIADOS A LA JERARQUÍA MILITAR}

Además de las anteriores, en el ejército se utilizan otras palabras que tienen, también, relación con el concepto de jerarquía. Veamos las más importantes, a continuación.

\subsection{Antigüedad}

Antigüedad es el tiempo transcurrido en el ejercicio de una determinada jerarquía. Veamos que dice de la misma, la vigente Ley 39/2007, de 19 de noviembre, de la carrera militar.

Artículo 23. Facultades y antigüedad en el empleo militar.

[...] 4. La precedencia de los militares estará determinada por el cargo o destino que se ocupe si está fijada en normas de carácter reglamentario; si no lo está se basará en el empleo; a igualdad de empleo, en la antigüedad en el mismo ${ }^{28}$ y a igualdad de ésta se resolverá a favor del de mayor edad.

Pero la antigüedad en el empleo no solo se considera entre los pertenecientes a un mismo escalafón, sino que se considera entre todos los miembros de las fuerzas armadas, como bien señala, por ejemplo, el siguiente artículo de las Reales Ordenanzas del Ejército de Tierra de 9 de noviembre de 1983:

\section{Artículo 279}

La disciplina halla su extensión externa en las muestras de respeto y subordinación entre militares, quienes, a estos efectos, se atendrán al orden jerárquico de empleo y antigüedad, independientemente del Ejército, Arma, Cuerpo o Escala a que pertenezcan.

El término precedencia que figura en el art. 23 de la Ley, significa, conforme al DRAE y en las acepciones que nos afectan

2. f. Anteposición, antelación en el orden. 3. f. Preeminencia o preferencia en el lugar y asiento y en algunos actos honoríficos. 4. f. Primacía, superioridad.

Y con estas definiciones es fácil deducir que la mayor antigüedad en el disfrute de un grado o empleo proporciona al militar, en términos relativos y con relación a otros de su mismo grado o empleo, mayor precedencia y consecuentemente mayor jerarquía.

\subsection{Consideración}

Consideración es otro de estos términos que, pese a no figurar en los diccionarios militares, tiene suficiente significado en los ejércitos como para hacer necesaria su inclusión en este trabajo.

\footnotetext{
${ }^{28}$ Destacado en negritas realizado por el autor.
} 
Señala doña María Moliner en su utilísimo Diccionario de uso del español, que consideración es la «actitud de estimación o respeto hacia una persona». Y en el ejército se utiliza este término, para referirse al derecho que se otorga a los componentes de determinados colectivos (civiles o militares), a ser tratados con la misma estimación y respeto que se debe a otros. La consideración puede referirse a una determinada categoría (por ejemplo, derecho a la consideración de oficial o de suboficial) o a un determinado empleo militar (por ejemplo, derecho a la consideración de coronel).

$\mathrm{Y}$ un aspecto muy importante a tener en cuenta es, que la consideración militar no tiene efectos retributivos, no aumenta la jerarquía militar ni se la proporciona al que no la tiene.

Con relación al personal civil, debemos recordar que, hasta la Ley 30/1984 de 2 de agosto, de medidas para la Reforma de la Función Pública, a los componentes de los cuerpos de funcionarios civiles al servicio de la Administración Militar, se les reconocía consideración militar de oficial o suboficial, según correspondiera en función de su nivel administrativo.

Un ejemplo muy conocido es el del extinto Cuerpo Especial de Damas Auxiliares de Sanidad Militar del Ejército de Tierra, cuyas componentes recibían consideración de suboficiales y vestían uniforme ${ }^{29}$; otro ejemplo, es el del, también extinto, Cuerpo Especial Facultativo de Meteorólogos del Ejército del Aire, a cuyos componentes, que tampoco tenían la condición militar, se les otorgaba la consideración de un determinado grado militar de oficial (capitán, comandante, etc.), se les permitía vestir el uniforme del Ejército del Aire con los emblemas de su cuerpo y a utilizar divisas ${ }^{30}$ del grado correspondiente ${ }^{31}$.

Con relación al personal militar, se puede citar como ejemplo el de los antiguos Cabos Primeros veteranos de la Armada, que eran conocidos como «cabos primeros chaqueta» por habérseles concedido la consideración de suboficiales, lo que les daba derecho a vestir el uniforme de suboficial (que constaba de chaqueta, como prenda superior, en lugar de la marinera tradicional que vestía el resto de la marinería), acceder a los pabellones de suboficiales y a ser tratados como tales ${ }^{32}$.

Desde 1983 los guardias civiles sin graduación, a partir de los seis años de servicio ininterrumpidos disfrutan de igual tratamiento y consideración que los Suboficiales, mientras que los cabos de la Guardia Civil tienen esa consideración desde el día que alcanzan ese empleo, si antes no la hubieran obtenido ${ }^{33}$.

\footnotetext{
${ }^{29}$ No debe confundirse este cuerpo con la Agrupación de Damas Auxiliares de Sanidad Militar, ya que éstas, a diferencia de las anteriores no eran personal funcionario, sino voluntarias.

${ }^{30}$ Sería más correcto decir distintivos en lugar de divisas, ya que en el ejército la palabra divisa alude a las insignias de la jerarquía militar y los componentes de este cuerpo no la tenían. Sin embargo, utilizo en este caso esta palabra porque utilizaban estrellas como el resto de los oficiales.

${ }^{31}$ Estas prerrogativas eran una reminiscencia de la época de la Guerra Civil en la que todos los meteorólogos fueron militarizados. Curiosamente, los componentes de la Escala Auxiliar de Meteorología del Ejército del Aire, a diferencia de los de la escala facultativa, sí tenían condición militar, con empleos desde sargento a comandante.

${ }^{32}$ La chaqueta de estos cabos primeros era, en su caso, divisa de categoría.

${ }^{33}$ Real Decreto 1970/1983, de 22 de junio, sobre consideración de suboficiales a las clases de tropa de la guardia civil.
} 
Actualmente los capellanes castrenses pueden vestir uniforme y usar sobre el mismo unos distintivos ${ }^{34}$ propios del servicio de asistencia religiosa de las Fuerzas Armadas que identifican la consideración militar que tienen, desde la consideración de capitán a la de coronel.

Finalmente, recordemos que «los militares de carrera al pasar a retiro cesarán definitivamente en la relación de servicios profesionales con las Fuerzas Armadas». «Tendrán la consideración de militar retirado» $\mathrm{y}$, entre otras prerrogativas, podrán «usar el uniforme en actos militares y sociales solemnes y disponer de la correspondiente tarjeta de identificación» ${ }^{35}$.

\subsection{Distinción}

En el ejército, distinción es un reconocimiento honorífico que, por razón de sus méritos, aplicación y/o ejemplar comportamiento, se hace a los alumnos de las academias militares y también se hacía a los soldados hasta $2007^{36}$. La distinción se explicita mediante un galón distintivo en el uniforme, que hace pública la que ha merecido por su conducta el que lo exhibe.

Cuando la distinción se concede como grado, como ha sido tradición con los soldados de primera ${ }^{37}$, representa un avance en la escala jerárquica que proporciona mayor autoridad. En este caso, el galón no debe considerarse distintivo sino divisa, pues expresa jerarquía.

En las academias, los alumnos a los que se otorga distinción reciben la denominación de sargentos o cabos galonistas, en función de la distinción que se les otorgue.

Esta clase de distinción que hemos descrito, basada en méritos y ejemplar comportamiento, se introduce en el ejército a mediados del siglo XIX, concretamente en Infantería en $1846^{38}$, y los soldados o marineros a los que se otorgaba recibieron, dependiendo del cuerpo y del momento, la denominación de soldados o marineros de distinción y la de soldados o marineros de primera, si bien soldado de primera, dependiendo

${ }^{34}$ Orden Ministerial 84/2011, de 18 de noviembre, por la que se desarrolla parcialmente, en materia de régimen de personal, el capítulo II del Real Decreto 1145/1990, de 7 de septiembre: «3. Los capellanes cuando utilicen uniforme usarán hombreras, manguitos o parches, según corresponda a cada Ejército, del color utilizado por el personal militar donde están destinados o comisionados, con el emblema del Arzobispado Castrense y los distintivos de la consideración de cada empleo, cuyo elemento característico estará constituido por un círculo con tres o cuatro líneas diametrales en su interior [...]».

${ }^{35}$ Ley 39/2007 de la Carrera Militar, art. 115.

${ }^{36}$ El punto 3 de la Disposición transitoria primera de la Ley 39-2007 de la Carrera Militar deroga las distinciones a la tropa: «A partir de la entrada en vigor de esta ley no se otorgará en el empleo de soldado o marinero la distinción del grado militar de soldado o marinero de primera. Los que tengan el grado de soldado o marinero de primera conservarán dicha distinción».

${ }^{37}$ La última ley que contempló la distinción de soldado de $1^{\text {a }}$ fue la Ley 17/1999 de personal militar que, en su artículo 47.2, decía: «En el empleo de Soldado existirá, como distinción, el grado de Soldado de Primera, que se otorgará en función del historial militar, de la forma que reglamentariamente se determine».

${ }^{38}$ Real Orden de 20 de junio de 1846. La Infantería fue la última de las armas en hacerlo pues en Artillería, Ingenieros y Caballería existían, desde años antes, los soldados de $1^{\mathrm{a}} \mathrm{y}$ de $2^{\mathrm{a}}$. 
de las épocas, fue calificado unas veces como distinción y otras como clase de tropa, al igual que cabo o sargento ${ }^{39}$.

La distinción ha conllevado siempre ciertos privilegios para los soldados o alumnos a los que se concede, como son el disfrute de mayor prelación y consideración que sus compañeros, estar excluidos de servicios mecánicos, disfrutar de mejores destinos y/o de alguna ventaja o sobresueldo, etc.

Antes de esa época y hasta 1842 , en que fueron suprimidos ${ }^{40}$, existieron los llamados soldados distinguidos, que no debemos confundir con los soldados de distinción que acabamos de describir, aunque a estos últimos se les diera también esta denominación debido a que la misma estaba muy enraizada en el ejército.

Los soldados distinguidos que contemplaba la ordenanza de 1768, lo eran no por sus méritos y ejemplar comportamiento, aunque esto también se les exigiera, sino por su extracción social: solo se daba esta consideración a los soldados que procedían de familia hidalga o eran hijos de capitán, al menos. Estos soldados eran, por lo general, jóvenes que deseaban ejercer la carrera militar y no habían podido sentar plaza como cadetes por carecer de asistencias para subsistir como tales. Entre otras consideraciones y privilegios que los diferenciaban significativamente del resto de la tropa, tenían derecho al tratamiento de Don y al uso de espada.

Otro tipo de distinción que se dio en el ejército durante los siglos XVIII y XIX era la que gozaban los soldados que integraban algunas compañías de soldados escogidos que había en los cuerpos, como las de granaderos y cazadores de los batallones de infantería de línea, o las de carabineros y tiradores de los batallones de infantería ligera. Se consideraba que estas compañías debían nutrirse con los mejores soldados y sus capitanes podían hacer elección o saca de los mismos, como decían las ordenanzas, de entre los que formaban en las restantes compañías de fusileros. La selección de estos soldados se hacía, fundamentalmente, por su destreza y cualidades físicas (altura y fortaleza). A comienzos del siglo XIX estas compañías que, además de preferencia para la elección de sus soldados, también la tenían en las formaciones y revistas, actos de pagamento, etc., comenzaron a denominarse compañías de preferencia ${ }^{41}$ y sus soldados, que disfrutaban de mayor sueldo y consideración que el resto, soldados de preferencia.

También debemos considerar entre los soldados con distinción que ha habido en los ejércitos españoles, a los soldados aventajados de la época de los Tercios. Esta denominación aparece en el siglo XVI para distinguir a aquellos que cobraban algún tipo de sobresueldo o ventaja, como se decía entonces. Esta ventaja solía concederse por diferentes razones. La Ordenanza de 8 de julio de 1632 establecía, entre otras, las siguientes: llevar más de doce años en filas; tener alguna especialidad, como la de coselete, arcabucero o mosquetero; realizar alguna acción de mérito durante el combate, como entrar el primero en navío enemigo, capturar la bandera enemiga, plantar la propia en la cima de una muralla, etc.

${ }^{39}$ La Ley de 4 de diciembre de 1931 establece que «Las clases de Tropa estarán constituidas, únicamente, por los soldados de segunda y de primera, los cabos y los sargentos».

${ }^{40}$ Decreto del Regente de 22 de febrero de 1842.

${ }^{41}$ Denominación tomada del francés «compagnie d'èlite» surgida en época de Napoleón. 
De la misma época es la denominación de soldado raso que, desde entonces, sirve para referirse, al soldado que no disfruta de ventaja o distinción alguna.

En resumen, la distinción en el ejército ha tenido como principal objetivo siempre, el proporcionar mayor consideración y, en determinados casos, mejor sueldo y mayor jerarquía. Y las motivaciones para concederla han sido diversas: premiar el comportamiento, la aplicación en el estudio, la antigüedad en el servicio, el esfuerzo en el combate, las cualidades físicas, las capacidades técnicas o subrayar la nobleza y extracción social.

\subsection{Condición}

La palabra condición es definida por el DRAE-2001, en la acepción que nos interesa, como:

3. f. Estado, situación especial en que se halla alguien o algo.

$\mathrm{Y}$ de nuevo, tenemos un concepto utilizado en las fuerzas armadas españolas que es necesario definir, por no estarlo en ningún diccionario ni reglamento. Este concepto es el de condición militar o condición de militar ${ }^{42}$ y podemos definirlo como «el estado en el que se halla el español que ejerce la profesión o actividad militar, y, en consecuencia, está sujeto al régimen general de derechos y deberes de los miembros de las Fuerzas Armadas y a las leyes penales y disciplinarias militares».

La condición militar es la que habilita la jerarquía individual en el ámbito de las fuerzas armadas. Por lo que, cuando se pierde o se suspende la condición de militar, se pierde o se suspende, también, esta jerarquía.

La pérdida de la condición militar puede ser definitiva, como sucede cuando un militar pasa a retiro o, simplemente, pide la baja en el ejército; o transitoria, como sucede con los reservistas que, en la situación de activado ${ }^{43}$ tienen la condición militar, deben cumplir las reglas de comportamiento del militar y están sujetos a las leyes penales y disciplinarias militares ${ }^{44} ; y$, cuando pasan a la situación de disponibilidad, pierden la condición militar pero conservan la de reservista y cierta consideración militar, como el derecho a vestir uniforme en actos castrenses o sociales ${ }^{45}$.

La vigente Ley 39/2007 de la Carrera Militar contempla cinco posibles modalidades de condición militar, para los españoles vinculados a las Fuerzas Armadas:

- Condición de alumno de la enseñanza de formación

- Condición de militar de carrera

\footnotetext{
${ }^{42}$ Se utilizan, indistintamente, ambas formas.

${ }^{43}$ Situación en la que se encuentra el reservista cuando, en virtud de su compromiso, está prestando servicios en su unidad militar de destino.

${ }^{44}$ Artículo 36«Régimen de personal», del Real Decreto 383/2011, de 18 de marzo, por el que se aprueba el Reglamento de Reservistas de las Fuerzas Armadas.

${ }^{45}$ Ley Orgánica 9/2011, de 27 de julio, de derechos y deberes de los miembros de las Fuerzas Armada: «Art. 52.2: 2. Mientras no se encuentren activados los reservistas no tienen condición de militar, si bien en sus relaciones con el Ministerio de Defensa, derivadas de tal condición, respetarán los cauces y normas de cortesía de aplicación en las Fuerzas Armadas, siendo acreedores igualmente al respeto y consideración debidos a su categoría militar».
} 
- Condición de militar de complemento

- Condición de militar de tropa y marinería

- Condición de reservista ${ }^{46}$

- $\quad$ Condición de prisionero o desaparecido ${ }^{47}$

Condición de alumno de la enseñanza de formación. Los alumnos que ingresan en los centros docentes militares tienen la condición militar, sin quedar vinculados por una relación de servicios profesionales, a partir del momento en que firman el documento de incorporación a las fuerzas armadas ${ }^{48}$.

Condición militar de carrera. La condición de militar de carrera se adquiere al obtener el primer empleo de la escala, excepto en el caso de los militares de tropa y marinería, que la adquieren cuando acceden a una prestación de servicios de carácter permanente 49

Condición de militar de complemento. La condición de militar de complemento se adquiere al adscribirse a una escala y cuerpo con el empleo de teniente y firmado un compromiso temporal $^{50}$.

Condición de militar de tropa y marinería. La condición de militar de tropa y marinería se adquiere al adscribirse a una escala de tropa o marinería y firmado un compromiso temporal ${ }^{51}$.

Condición de reservista es el estado en el que se hallan los españoles que, en aplicación del derecho y deber constitucionales de defender a España, pueden ser llamados a incorporarse a las Fuerzas Armadas. Se les denomina reservistas, término que se utiliza en el ejército desde el siglo XIX, y su condición militar y jerarquía, dependen de su situación, como se verá más adelante.

La legislación actual prevé tres clases de reservistas: voluntarios, de especial disponibilidad y obligatorios ${ }^{52}$.

La condición de reservista voluntario la adquiere todo español que habiendo solicitado participar en la correspondiente convocatoria resulte seleccionado, supere los periodos de formación militar, básica y específica, que reglamentariamente se determinen para adquirir tal condición y firme un compromiso inicial.

Adquieren la condición de reservistas de especial disponibilidad los Militares de Tropa y Marinería y los Militares de Complemento ${ }^{53}$ que voluntariamente lo soliciten

\footnotetext{
${ }^{46}$ No debe confundirse la condición de reservista con la situación de reserva, que se verá más adelante.

${ }^{47}$ Condición incorporada a la ley por el artículo 40 del Real Decreto 1111/2015, de $11 \mathrm{de} \mathrm{di-}$ ciembre, por el que se aprueba el Reglamento de adquisición y pérdida de la condición de militar y situaciones administrativas de los militares profesionales.

${ }^{48}$ Ley 39/2007 de la Carrera Militar, art. 67.

${ }^{49}$ Real Decreto 1111/2015, de 11 de diciembre, por el que se aprueba el Reglamento de adquisición y pérdida de la condición de militar y situaciones administrativas de los militares profesionales, art. 4.

${ }^{50}$ Ibid., art. 7.

${ }^{51}$ Ibid., art. 9.

${ }^{52}$ Ley 39/2007 de la Carrera Militar, arts. 122, 125.2 y 136.
} 
al finalizar sus compromisos de larga duración, tengan 45 años y acrediten haber cumplido al menos dieciocho años de servicios ${ }^{54}$. Estos reservistas adquieren el compromiso de ser activados e incorporarse a las fuerzas armadas cuando, en situaciones de crisis, lo disponga el gobierno. Pueden mantener esta condición hasta los 65 años y perciben una asignación por disponibilidad, distribuida en 12 mensualidades.

Adquieren la condición de reservista obligatorio, los españoles cuya edad esté comprendida entre los 19 y los 25 años que, para satisfacer las necesidades de la defensa nacional, con la autorización previa del Congreso de los Diputados y después de un proceso de selección, fueran declarados como tal mediante un real decreto. Cesarán en esta condición el 31 de diciembre del año en que cumplan 25 años ${ }^{55}$.

Los reservistas voluntarios y de especial disponibilidad pueden tener empleos en las categorías de Oficial y Suboficial y Tropa y Marinería. Los reservistas obligatorios tendrán, únicamente, los empleos de soldado o marinero.

Condición de prisionero es el estado en el que se encuentra el militar que ha sido prendido y se encuentra sometido a cautiverio por razón de su condición militar, por componentes de fuerzas, organizaciones, o bandas enemigas u hostiles ${ }^{56}$. El militar que se encuentra prisionero conserva su condición militar y el derecho a ser tratado con la consideración que le corresponde por su graduación y edad ${ }^{57}$.

Condición de desaparecido es el estado en que se encuentra el militar que con ocasión del servicio resulte ilocalizable debido a causas atribuibles al cumplimiento de sus obligaciones militares ${ }^{58}$. La condición de desaparecido no implica pérdida de la condición militar; conservándose esta, a todos los efectos, hasta que legalmente se declare el fallecimiento ${ }^{59}$.

\subsection{Asimilación}

El DRAE-2001 define asimilación como:

${ }^{53}$ En el caso de los militares de complementos, solo pueden optar a ser reservistas de especial disponibilidad los procedentes de la Ley 17/1999, de 18 de mayo.

${ }^{54}$ Ley 8/2006, de 24 de abril, de Tropa y Marinería, art. 17. Ley 39/2007 de la Carrera Militar, disposición transitoria quinta.

${ }_{55}^{5}$ Real Decreto 383/2011, de 18 de marzo, por el que se aprueba el Reglamento de Reservistas de las Fuerzas Armadas, arts. 2c y 59.

${ }^{56}$ Real Decreto $1111 / 2015$, art. 40.a

${ }^{57}$ III Convenio de Ginebra del 12 de agosto de 1949 relativo al trato debido a los prisioneros de guerra, arts. 44 y 45.

${ }^{58}$ Ibid., art. $40 . \mathrm{b}$

${ }^{59}$ Conforme a lo indicado en el art. 194.1 del Código Civil, procederá la declaración de fallecimiento de un militar desaparecido en campaña, cuando hayan transcurrido, al menos dos años desde la firma del tratado de paz o de la declaración oficial de fin de la guerra.

Por otro lado el Real Decreto 1111/2015 señala en su art. 42 que «en el caso de los militares desaparecidos, el tiempo en que permanecerán en la situación de servicio activo, estará limitado a dos años desde la declaración de desaparecido. Pasado ese plazo, se reputará exclusivamente a los efectos militares como fallecido, publicándose la baja en el Boletín Oficial del Ministerio de Defensa. 3. El plazo anterior se reducirá a tres meses para el mismo grupo de militares cuando se encontraran a bordo de un buque naufragado, de una aeronave siniestrada o militares desaparecidos por inmersión en el mar, sin haberse tenido noticias de ellos, ni haberse encontrado sus restos». 
De Asimilar: 2. tr. Conceder a los individuos de una carrera o profesión derechos u honores iguales a los que tienen los individuos de otra.

En el siglo XVIII se vio la necesidad de integrar en el propio ejército, y sometidos a la ordenanza y disciplina militar, a individuos que ejercían profesiones ajenas a la de las armas, propiamente dicha, pero que eran necesarias en el ámbito militar; como son las de médico, farmacéutico, veterinario, ingeniero, jurista, sacerdote, etc.

Estos individuos adquirían la condición militar y continuaban ejerciendo su profesión dentro del ejército, en cuerpos y escalas específicas que tenían grados y empleos con denominaciones propias, pero que estaban asimilados a los de las escalas de los cuerpos y armas tradicionales (Infantería, Artillería, Caballería, etc.), lo que les proporcionaban jerarquía militar.

En el Ejército de Tierra, por ejemplo, fueron cuerpos de asimilados, entre otros, los de Sanidad Militar, Intendencia, Clero Castrense, Jurídico e Intervención, Equitación, Oficinas Militares, Directores de Música y Brigada Obrera Topográfica de Estado Mayor.

$\mathrm{Y}$ en cuanto a las denominaciones de los empleos, los sacerdotes que ejercían de capellanes castrenses tenían empleos como el de capellán segundo, asimilado a teniente o el teniente vicario de segunda, asimilado a teniente coronel; en el caso de los farmacéuticos, existía, por ejemplo, el empleo de farmacéutico primero asimilado a capitán; en el de oficiales de equitación, el de subinspector segundo de equitación, asimilado a teniente coronel; entre los jurídicos, el de auditor de brigada, asimilado a teniente coronel; entre los músicos el de director de música de tercera, asimilado a teniente; etc.

En la segunda mitad del siglo XX, las escalas de militares asimilados desaparecieron o se transformaron en escalas de militares de carrera, como las de los cuerpos y armas tradicionales ${ }^{60}$.

\subsection{Situación}

Situación es una palabra que, en el ejército y en lo que afecta a la jerarquía, sirve para describir la relación administrativa de los militares con el Estado, respecto del ejercicio de su profesión.

Actualmente las situaciones administrativas de los militares profesionales, conocidas como situaciones militares, son las siguientes ${ }^{61}$ :
a) Servicio activo.
b) Servicios especiales.
c) Excedencia.
d) Servicio en la Administración civil
e) Suspensión de funciones.

${ }^{60}$ En la actualidad, por ejemplo, médicos, veterinarios, farmacéuticos, juristas e ingenieros son militares de carrera, no así los capellanes castrenses que por virtud del Real Decreto 1145/1990 han perdido su condición militar y, desde entonces, están integrados en el denominado Servicio de Asistencia Religiosa en las Fuerzas Armadas.

${ }^{61}$ Real Decreto 1111/2015, de 11 de diciembre, por el que se aprueba el Reglamento de adquisición y pérdida de la condición de militar y situaciones administrativas de los militares profesionales, art. 12. 
f) Suspensión de empleo.

g) Reserva.

Veamos, a continuación, y de acuerdo con la legislación vigente, los efectos que estas situaciones producen en la jerarquía militar.

Comencemos señalando que, conforme a la ley ${ }^{62}$, el militar profesional se encuentra en la situación de Servicio activo cuando ocupa un cargo o destino, se halla pendiente de asignación de destino o permanece como alumno en un centro militar de enseñanza. Cuando se encuentra en esta situación y ocupando destino o como alumno, el militar está en plenitud de su jerarquía individual y circunstancial, derechos y deberes. Cuando no ocupa destino, el militar no tiene jerarquía efectiva, pues, aunque conserva su jerarquía individual, no puede ejercerla.

El militar profesional, conforme a la ley ${ }^{63}$, pasa a la situación de Servicios especiales cuando es designado, nombrado, autorizado, elegido o proclamado para ocupar determinados cargos de naturaleza política, pública o privada en el Gobierno, las Cortes Generales, administraciones públicas, entidades u organismos nacionales o internacionales, empresas públicas, etc.

El militar profesional pasa a la situación de Excedencia, cuando, de acuerdo con las modalidades previstas en la ley ${ }^{64}$, se aprueba su solicitud de dejar de ejercer temporalmente la profesión militar, y pasa a la situación de Servicio en la Administración Civil, cuando, de acuerdo con lo dispuesto en la ley ${ }^{65}$, es autorizado a ocupar un puesto de trabajo en ella.

En las situaciones de Servicios especiales, Excedencia y Servicio en la Administración Civil, la condición militar queda en suspenso y, en consecuencia, los militares que pasan a alguna de ellas dejan de estar sujetos al régimen general de derechos y deberes de los miembros de las Fuerzas Armadas y a las leyes penales y disciplinarias militares; lo que conlleva la pérdida de su jerarquía militar durante el tiempo que están en estas situaciones.

El pase a la situación de Suspensión de funciones del militar profesional se podrá acordar como consecuencia del procesamiento, inculpación o adopción de alguna medida cautelar contra el imputado en un procedimiento penal o por la incoación de un procedimiento disciplinario por falta muy grave ${ }^{66}$.

En la situación de Suspensión de funciones el militar conserva su condición militar, su empleo con el $75 \%$ de las retribuciones básicas ${ }^{67}$, y el derecho a ser tratado con la consideración que merece por su categoría y empleo, pero, al ser suspendido en el ejer-

${ }^{62}$ Ibid., art. 16.

${ }^{63}$ Ibid., art. 18.

${ }^{64}$ Ibid., art. 24.

65 Ibid., art. 36.

${ }^{66}$ Ibid., art. 31

${ }^{67} R D$ 1314/2005, de 4 de noviembre, por el que se aprueba el Reglamento de retribuciones del personal de las Fuerzas Armadas (modificado por el Real Decreto 789/2007, de 15 de junio) $\rightarrow$ «Art. 8. Situaciones de suspenso de empleo y de suspenso de funciones. En estas situaciones se percibirá el $75 \%$ de las retribuciones básicas». 
cicio de sus funciones no puede ejercer su autoridad y, en consecuencia, carecerá de jerarquía efectiva mientras permanezca en esta situación.

A diferencia de la situación de Suspensión de funciones, que es provisional y a la que se pasa en tanto se sustancia un procedimiento, el pase de un militar a la situación de Suspensión de empleo se produce cuando es condenado, en sentencia firme, a la pena de prisión o se le impone una sanción disciplinaria de suspensión de empleo por falta muy grave. El Ministro de Defensa también podrá acordar el pase de los militares profesionales a la situación de suspensión de empleo a la vista de la sentencia en que se impusiera la pena de inhabilitación especial para profesión, oficio o cualquier otro derecho, cuando dicha inhabilitación impida o menoscabe el ejercicio de sus funciones ${ }^{68}$.

La situación de suspensión de empleo produce «los mismos efectos que los establecidos para la situación de suspensión de funciones» ${ }^{69}, \mathrm{y}$, además, el cese en el destino, si el paso a esta situación se produce por sanción disciplinaria superior a seis meses, por lo que, de igual manera, el militar carecerá de jerarquía mientras permanezca en esta situación.

Tienen acceso a la situación de Reserva, únicamente los militares de carrera ${ }^{70}$, los cuales pasarán a la misma cuando alcancen una determinada edad ${ }^{71} \mathrm{o}$ un determinado tiempo en algunos empleos ${ }^{72}$, también por decisión del gobierno o cuando, cumplidos ciertos requisitos, lo solicita voluntariamente. En esta situación el militar conserva su empleo y condición militar y puede dejar de ocupar destino, continuar ocupando alguno de los destinos habilitados para militares en esta situación o ser nombrado para una comisión de servicio.

El militar en situación de Reserva que no ocupa destino, aunque conserva su condición militar y empleo, en la práctica ya no puede ejercer ninguna jerarquía, por lo que se considera que ha dejado de tener jerarquía militar efectiva. Sin embargo, el militar en situación de Reserva que ocupa un destino o está en comisión de servicio mantiene efectiva su jerarquía, ya que la ley contempla que «El militar profesional en situación de reserva, destinado o en comisión de servicio, ejercerá la autoridad y funciones que le correspondan según su empleo y cuerpo, con exclusión del ejercicio del mando en la Fuerza de los Ejércitos» ${ }^{73}$.

${ }^{68}$ Real Decreto 1111/2015, de 11 de diciembre, por el que se aprueba el Reglamento de adquisición y pérdida de la condición de militar y situaciones administrativas de los militares profesionales, arts. 34.1 y 34.2 .

${ }^{69}$ Ibid., art. 34.3

${ }^{70}$ Los militares de Tropa y Marinería y Militares de Complemento con más de dieciocho años de servicios, al finalizar sus compromisos de larga duración pueden solicitar el paso a la condición de Reservistas de especial disponibilidad cuando cumplan 45 años, de conformidad con lo dispuesto en el art. 17 de la Ley 8/2006, de 24 de abril, de Tropa y Marinería y en la disposición transitoria quinta de la Ley 39/2007, de 19 de noviembre, de la Carrera Militar.

${ }^{71}$ Actualmente la edad de pase a la reserva para los militares de carrera de las categorías de Oficiales y Suboficiales es 61 años y de 58 en la categoría de Tropa y Marinería (art. 113.4 de la Ley 39/2007, de 19 de noviembre, de la Carrera militar).

${ }^{72}$ Por ejemplo, 6 años en el empleo de Coronel o en el de Suboficial Mayor. 4 años en el empleo de General de brigada, etc.

${ }^{73}$ Ley 39/2007, de 19 de noviembre, de la Carrera militar, art. 113.8. 


\subsubsection{Situaciones de los reservistas}

El Real Decreto 383/2011, de 18 de marzo, por el que se aprueba el Reglamento de Reservistas de las Fuerzas Armadas, contempla dos situaciones para este personal:

a) Activado

En la situación de Activado, los reservistas prestan servicio en las unidades, centros u organismos del Ministerio de Defensa, tienen la condición militar, deben cumplir las reglas de comportamiento militar, están sujetos a las leyes penales y disciplinarias militares y les es de aplicación el régimen de personal de los militares profesionales de empleo equivalente y en la situación de servicio activo. Además, durante el tiempo de activación podrán ejercer las atribuciones disciplinarias que les correspondan en función del empleo que ostenten y del puesto orgánico ocupado.

En consecuencia, a efectos de jerarquía, debemos entender que un reservista en situación de Activado y prestando servicios en el puesto asignado, tiene la misma jerarquía individual que un militar profesional de su mismo empleo que se encuentre en situación de Servicio activo y ocupando destino.

En situación de Disponibilidad, los reservistas no tienen la condición de militar ni prestan servicio en las Fuerzas Armadas, pero pueden ser llamados a incorporarse a las mismas. Obviamente, en esta situación no tienen ninguna jerarquía militar.

\subsection{Retiro}

Retiro es el término utilizado, tradicionalmente, en el ejército para designar el estado al que pasan los militares de carrera ${ }^{74}$ cuando finalizan su vida profesional. Y, si al hablar del personal civil que finaliza su vida profesional, decimos que se jubila y que, en consecuencia, se convierte en un jubilado, al hablar del personal militar, decimos que se retira o pasa a retiro y que, en consecuencia, se convierte en un militar retirado.

Así lo dispone el artículo 115 de la ley 39/2007 de la Carrera Militar:

Artículo 115. Militares retirados:

Los militares de carrera al pasar a retiro cesarán definitivamente en la relación de servicios profesionales con las Fuerzas Armadas y dejarán de estar sujetos al régimen general de derechos y deberes de los miembros de las Fuerzas Armadas y a las leyes penales y disciplinarias militares.

Tendrán la consideración de militar retirado.

Este cese en la relación de servicios profesionales con las Fuerzas Armadas implica la pérdida de la condición militar y, en consecuencia, de la jerarquía militar, pero no desvincula totalmente del ejército a los militares retirados, ya que conservan, como señala la ley, la «consideración de militar retirado», que les da derecho a ser tratados con el respeto que merecen por su categoría y empleo y, además, según lo que dispone el mismo artículo,

${ }^{74}$ Los militares de complemento y los militares de tropa y marinería que mantienen una relación de servicios de carácter temporal, pasan a la situación legal de desempleo cuando finaliza o se resuelve el compromiso que tienen suscrito con las fuerzas armadas (Ley 39/2007 de la Carrera Militar, art. 118.2). 
Mantendrán, si lo solicitan, una especial relación con las Fuerzas Armadas, mediante su adscripción a la unidad militar que elijan, previa conformidad del Mando o Jefatura de Personal del Ejército correspondiente. Podrán asistir a actos y ceremonias militares en los que dicha unidad participe, usar el uniforme en actos militares y sociales solemnes y disponer de la correspondiente tarjeta de identificación.

Es bastante frecuente escuchar, incluso en el propio ámbito militar, que tal persona ha pasado a la situación militar de retiro o que tiene la condición militar de retirado: en ambos casos se comete un claro error ya que retiro y retirado no figuran, respectivamente, entre las situaciones y condiciones militares contempladas en la ley.

$\mathrm{Y}$ aunque la propia ley evita las complicaciones utilizando la expresión pasar a retiro que, por otro lado es tradicional en el lenguaje militar, se puede afirmar que retiro no es otra cosa que una situación administrativa, y por la tanto si es correcto decir, por ejemplo, que tal persona se encuentra en situación de retiro o que tiene la condición de retirado $\mathrm{o}$, incluso, que tiene la condición de militar retirado ${ }^{75}$.

\section{CONCLUSIONES}

La jerarquía, como demostraron Dunbar y Aiello, es consustancial con la naturaleza humana, y el instrumento que permite a los hombres formar grupos que actúen como uno solo. En su aplicación a los ejércitos, es un concepto vertebrador de la organización militar y una de las señas más características de su identidad.

La autoridad militar emana de la jerarquía y conlleva, como atributos, Poder, Responsabilidad, Consideración y Precedencia, siendo PODER, ESTATUS y NIVEL JERÁRQUICO las ideas principales que transmiten los términos de la jerarquía utilizados en el ejército.

El significado de muchos términos de la jerarquía militar se encuentra en las leyes y es afectado por su evolución.

La evolución de las leyes y la adopción de extranjerismos han introducido confusión en el significado y uso de algunos términos de la jerarquía militar.

\section{REFERENCIAS BIBLIOGRÁFICAS}

AIELLO, Leslie y Robin DUNBAR (1993): «Neocortex size, group size and the evolution of language», Current Anthropology, 34, pp. 184-193.

AlbadAlejo ASENSIO, María Isabel (2015): La evolución de los sistemas de ascenso y de provisión de destinos en el ejército, Madrid, Universidad Nacional de Educación a Distancia, Instituto Universitario general Gutiérrez Mellado.

Almirante, José (1989 [1873]): Diccionario Militar, Madrid, Ministerio de Defensa.

Covarrubias, Sebastián de (2001 [c 1611]): Suplemento al Tesoro de la lengua española castellana, edición de Georgina Dopico y Jacques Lezra, Madrid, Polifemo.

\footnotetext{
${ }^{75}$ Nótese la importancia de la preposición de en esta expresión.
} 
FERnÁNDEZ MANCHEÑO, José (1822): Diccionario militar portátil, Madrid, Imprenta de Miguel de Burgos

García Vera, Ma José y Ma Concepción CASTRILlo Llamas (1993): «Nobleza y poder militar en Castilla a fines de la Edad Media», Boletín de la Sociedad Española de Estudios Medievales, 3, pp. 39-58.

LONDOÑO, Sancho de (1993 [1596]): El discurso sobre la forma de reducir la disciplina militar a mejor y antiguo estado, Madrid, Ministerio de Defensa, Secretaría General Técnica.

MANDO DE AdiESTRAMIENTO Y DoctRINA (2000): Glosario de términos militares. D02005, Dirección de Servicios Técnicos del Ejército.

Moliner, María (1975): Diccionario de uso del español, Madrid, Gredos.

ReAl ACADEMia EsPañola (2001): Diccionario de la lengua española, Madrid, Espasa, vigésima segunda edición [DRAE-2001].

ReAl ACADEMIA EsPañola: Banco de datos CORDE [en línea]. Corpus diacrónico del español. $<$ http://www.rae.es>

SEdAno Lorenzo, Alfonso y Álvaro CASAsola Gómez-Aguado (2012): «Las consecuencias jurídico-administrativas del militar delincuente (y presunto)», Revista jurídica de Castilla y León, 27, pp. 1-42.

TEXTOS LEGALES ${ }^{76}$

Colección de decretos y órdenes de las Cortes de Cádiz, Madrid, Publicaciones de las Cortes Generales, 1987, 2 t.

Real Decreto de 30 de julio de 1866, Gaceta de Madrid, 212 (31 de julio de 1866).

Ley Adicional a la Constitutiva del Ejército de 19 de julio de 1889, Gaceta de Madrid, 201 (20 de julio de 1889).

Decreto Ley de 16 de junio de 1931, Gaceta de Madrid, 168 (17 de junio de 1931), p. 1435.

Ley de 4 de diciembre de 1931, Gaceta de Madrid, 339 (5 de diciembre de 1931).

Ley de 4 de julio de 1934, Gaceta de Madrid, 193 (12 de julio de 1934).

Ley 30/1984 de 2 de agosto, de medidas para la Reforma de la Función Pública, Boletín Oficial del Estado, 185 (3 de agosto de 1984), pp. 22629-22650.

Ley 17/1989, de 19 de julio, reguladora del Régimen del Personal Militar Profesional, Boletín Oficial del Estado, 172 (20 de julio de 1989), pp. 23129-23147.

Ley 17/1999, de 18 de mayo, de Régimen del Personal de las Fuerzas Armadas, Boletín Oficial del Estado, 119 (19 de mayo de 1999), pp. 18751-18797.

Ley 8/2006, de 24 de abril, de Tropa y Marinería, Boletín Oficial del Estado, 98 (25 de abril de 2006).

Ley 39/2007, de 19 de noviembre, de la carrera militar, Boletín Oficial del Estado, 278 (20 de noviembre de 2007).

Real Decreto 494/1984, de 22 de febrero, por el que se aprueban las Reales Ordenanzas del Ejército del Aire, Boletín Oficial del Estado, 61 (12 de marzo de 1984), pp. 6869-6886.

Real Decreto 1970/1983, de 22 de junio, sobre consideración de suboficiales a las clases de tropa de la guardia civil, Boletín Oficial del Estado, 173 (21 de julio de 1983).

${ }^{76}$ Seguimos una ordenación cronológica en este apartado bibliográfico. 
Real Decreto 96/2009, de 6 de febrero, por el que se aprueban las Reales Ordenanzas para las Fuerzas Armadas, Boletín Oficial del Estado, 33 (7 de febrero de 2009).

Real Decreto 383/2011, de 18 de marzo, por el que se aprueba el Reglamento de Reservistas de las Fuerzas Armadas, Boletín Oficial del Estado, 70 (23 de marzo de 2011).

Real Decreto 1111/2015, de 11 de diciembre, por el que se aprueba el Reglamento de adquisición y pérdida de la condición de militar y situaciones administrativas de los militares profesionales, Boletín Oficial del Estado, 297 (12 de diciembre de 2015).

\author{
TÍTUlo/Title \\ «La jerarquía militar. Conceptos y terminología» \\ «The military hierarchy. Concepts and terminology»
}

Fecha de recepción: 20/09/2017 Fecha de aceptación: 29/01/2018

Resumen: Desde los inicios de su deambular terrestre, los seres humanos conformaron grupos jerarquizados que les permitían realizar con eficacia aquellas tareas que eran imprescindibles para su supervivencia, como la caza, la guerra y, posteriormente, las labores agrícolas y otras muchas.

Las estructuras jerárquicas fueron haciéndose cada vez más complejas, a medida que la sociedad humana se desarrollaba, y, en la misma medida, lo hizo el lenguaje, incorporando palabras y expresiones que facilitaban la comunicación y servían mejor al ejercicio de cada una de estas tareas. Y, de todas ellas, la guerra, por su transcendencia e importancia, es la que ha requerido constituir, para su eficaz desempeño, una organización compleja, fuertemente jerarquizada y dotada permanentemente de recursos e individuos, a la que denominamos ejército.

El lenguaje militar, o lenguaje que se utiliza en el ejército tiene características propias que contribuyen a la eficacia, siendo una de las más importantes la precisión lingüística. Para lograrlo, los militares disponen de un léxico que es específico, abundante y preciso y, en la comunicación, procuran utilizar un estilo claro, conciso y concreto.

El propósito de este trabajo es mostrar el léxico español relacionado con la jerarquía militar, explicando el significado de cada palabra y subrayando, cuando procede, las diferencias entre algunas de ellas que pertenecen a un mismo campo semántico, con objeto de que se pueda apreciar la complejidad y la diversidad de conceptos que utiliza el lenguaje militar en este ámbito.

Palabras clave: jerarquía; militar; léxico; terminología; lenguaje.

Abstract: From the beginnings of their time on Earth, human beings have formed hierarchical groups that allowed them to perform effectively those tasks that were essential for their survival, such as hunting, war and, later, agricultural work and many others.

These hierarchical structures became increasingly complex over time, as human society and language developed, incorporating words and expressions that facilitated communication and were better suited for each of these tasks. Amongst all of them, war, due to its transcendence and importance, required a complex organization in order to perform effectively, and led to highly hierarchical institution permanently endowed with resources and individuals, which we call the army.

The military language, or language used in the army, has its own characteristics that contribute to effectiveness, one of the most important being linguistic precision. To achieve this, the military has a lexicon that is specific, abundant and precise and, in communication, they try to use a clear, concise and concrete style. 
The purpose of this work is to show the Spanish lexicon related to the military hierarchy, explaining the meaning of each word and underlining, when appropriate, the nuanced differences between some of them which belong to the same semantic field, in order to appreciate the complexity and diversity of concepts in use within this area.

Keywords: hierarchy; military; lexicon; terminology, language. 